\title{
Who Are The Tourists?
}

\section{Christine PETR}

Laboratoire d'économie et de gestion de l'Ouest

Université Bretagne Loire, France

Corresponding Author: christine.petr@univ-ubs.fr

\section{ARTICLE INFO}

Received

20 January 2020

Accepted

18 March 2020

Available online

31 March 2020

\section{ABSTRACT}

Tourism is the subject of much research and evaluation at the national or international level. however, tourism remains under-theoretical and defining tourism has long been a challenge for those studying this field. Whether it is a question of quantifying flows, measuring the importance of recurrent and emerging practices, or identifying motivations for choosing destinations and activities, one of the priorities is to be able to accurately identify the subject of study. Purpose of the study are to review (i) who is the author of these socalled "tourist" trips and stays?, and (ii) who can be classified as a tourist? method is based on on the review of some literatures related to the topic. The results show that contextualized and recalled the definitions of tourists based on the recommendations made since IRTS 2008 by the supranational organization for the promotion of tourism on a global scale

Keywords: foreigners, holiday makers, visitors, multicultural exchanges

\section{INTRODUCTION}

There has been understoot that tourism is the subject of much research and evaluation at the national or international level. however, tourism remains under-theoretical and defining tourism has long been a challenge for those studying this field. Measuring the importance of recurrent and emerging practices, or identifying http://ojs.unud.ac.id/index.php/eot motivations for choosing destinations and activities, is one of the priorities that be able to accurately identify.

This study reviews

(i) who is the author of these so-called "tourist" trips and stays?, and

(ii) who can be classified as a tourist? method is based on on the review of some literatures related to the topic. 


\section{LITERATURE REVIEW}

\section{Define the tourist: between evidence and needs for precision}

Tourism is the subject of much research and evaluation at the national or international level. However, tourism remains under-theoretical (Liburd, 2002; Demen-Meyer, 2005) and defining tourism has long been a challenge for those studying this field (Boyer, 1972). Whether it is a question of quantifying flows, measuring the importance of recurrent and emerging practices, or identifying motivations for choosing destinations and activities, one of the priorities is to be able to accurately identify the subject of study (Williams, 2004). So who is the author of these so-called "tourist" trips and stays? Who can be classified as a tourist?

Beyond the answers that come spontaneously (e.g.: $\quad$ "foreigners"; "holidaymakers who come to us"; "we ourselves when we go elsewhere"; "everyone") and which refer to the socalled "popular" definition (Leiper, 1993), the qualification of tourist status must be considered with finesse and rigour to meet academic and technical ambitions. It is not enough to ask the question "where do you live? "and to note the difference between the place of study and nationality. Indeed, being a tourist goes beyond the simple fact of coming from an area of geographical or administrative origin different from the one in which you are currently living. It is also necessary to consider the time dimension of the stay. It is also necessary to take into account the motivations and activities that are carried out in this geographical area of temporary residence. These three dimensions make it possible to explain and understand more precisely the variations in tourist behaviour and reactions. Their knowledge then allows and implies the necessary adaptations both for the management of receiving and sending tourism companies and for the economic and social development of the destination.

Considering this need for a detailed definition of the tourist, this chapter is divided into two stages. First, the ambition is to recall the context and issues that have governed the selection of the criteria for characterizing the statistical unit of tourism that is the individual tourist. Secondly, it is a question of specifying the three perimeters, spatial, temporal and functional (i.e. motivations and activities) that must be considered in order to precisely define tourists and thus better situate their expectations and needs in view of the different tourist populations they constitute. 
Context, issues and definition of the tourist

After a presentation of the structuring of UNTWO and its participation in the development of a harmonised and usable reference framework for the measurement of tourism by all nations, the definitions of the four reference tourist units are presented.

\section{The progressive structuring of definitions}

If the need for definitions was expressed in 1934 by the International Union of Official Tourist Propaganda Organizations and confirmed by the Council of the League of Nations in 1937, this need became more acute after the Second World War. Indeed, the world that was being rebuilt was relying in part on tourism to re-establish peaceful exchanges between countries and nations. Thus, in 1954, what is now UNWTO (United Nation World Tourism Organization) participated in the United Nations Conference on Customs Formalities to facilitate and promote tourism. And it was at the initiative of this supranational body that, in 1963, at the United Nations conference in Rome, technical cooperation and the promotion of freedom of movement were discussed.
In this post-war period, the argument for tourism development is based above all on economic potential (i.e. tourism as a vehicle for development) and on the strengthening of interindividual and multicultural exchanges (i.e. tourism as a vehicle for peace thanks to the increased sociability between inhabitants of the various nations and between inhabitants of the various regions within each nation). Today, the argument in support of tourism development is broadened since there is a regular discussion, especially since 2017, which was the International Year of Tourism for Sustainable Development, of highlighting the contribution of tourism to raising awareness of the need to protect the environment and preserve local cultures (Highlights UNTWO 2017).

To meet these challenges of promoting tourism, it is necessary to be able to demonstrate the usefulness of tourism to leaders and political actors in all countries of the world. The prerequisites are therefore to be able, on the one hand, to prove its quantitative importance on a global and country-bycountry basis and, on the other hand, to be able to assess, in figures, the economic and social development potential for each destination. 
As an economically studied phenomenon (Py, 2007), it is a question of how to measure volumes and flows of travellers. In the end, this makes it possible to calculate the direct and indirect economic benefits linked to these volumes by using figures relating to overnight stays and tourist visitor spending.

As such, five key figures related to economic development are regularly highlighted at the global level: 1) the number of jobs, 2) the weight in world GDP, 3) the turnover of world exports linked to international tourism activity, 4) the share that this represents in total world exports, and 5) the relative share if we consider only exports of services. Thus, for 2017, UNTWO announces performances that are respectively: 1 in 10 jobs in the world is related to tourism, tourism represents $10 \%$ of world GDP, which reaches 1,400 billion Dollar (USD) of world exports, or $7 \%$ of world exports for tourism alone, and corresponds to $30 \%$ of exports of services.

A historical review of the structure and actions of UNWTO, summarized in a table (Table 1), shows the steps in the pursuit of this characterization objective for international measurement purposes. A quick reading of this table reveals three key dates in the history of the conceptualization and statistical http://ojs.unud.ac.id/index.php/eot measurement of tourism:

a. 1963, with the Rome Conference, where the recommendations made by what would later become UNWTO, to define the tourist and to distinguish him from other related concepts such as the visitor, the traveller and the excursionist, were accepted by the United Nations.

b. 1991, with the Ottawa conference, where the principle of building a common and harmonized global reference framework for tourism measurement methods at the national and international levels was validated.

However, this intention is not translated into a priority and is only really operationalized as from 2004 with the decision of the United Nations Statistical Commission (Official Records of the Economic and Social Council 2004, Supplement No. 4 (E/2004/24), Chap. III C. para.6 (c and d)) to design a set of recommendations for tourism statistics.

a. 2008, with the proposal by UNTWO for a tourism glossary that is the result of two years of work by the international community (UNWTO, 2005/2007).

The ambition is to propose definitions and classifications that can be integrated into all national tourism 
statistics systems. Despite the priority given to measurement, however, economics is no longer the only grid to be used, since these conceptual and statistical recommendations aim to provide a common basis for all research and surveys on tourism, whether the prism is social, cultural or economic.

These international recommendations were finally and definitively approved by the United Nations in 2014. They are the subject of the publication in 2016 of the "IRTS 2008 Compilation Guide" which is, to date, the standard to be used.

Table 1. History of definitions and approvals of units of measurement and statistical elements of tourism

\begin{tabular}{|c|c|}
\hline Date & $\begin{array}{c}\text { Creation of organizations (UIOOP, UIOOT, WTO, UNWTO) } \\
\text { and Statistical Recommendations }\end{array}$ \\
\hline 1934 & Creation of the UIOOP (International Union of Official Tourist Propaganda Organizations) \\
\hline 1937 & $\begin{array}{l}\text { The Council of the League of Nations (future UN) recommends the establishment } \\
\text { of a definition of "international tourist" for statistical purposes }\end{array}$ \\
\hline 1946 & 1st International Congress of National Tourism Organisations \\
\hline 1947 & $\begin{array}{l}\text { Creation of the IUOTO (International Non-Governmental Organisation): International } \\
\text { Union of Official Tourism Organisations }\end{array}$ \\
\hline 1948 & UIOOT obtains consultative status with the United Nations \\
\hline 1950 & Partial amendment of the definition of international tourist (Dublin) \\
\hline 1963 & $\begin{array}{l}\text { Adoption of the recommendations made by the IUOTO on the definition of the terms } \\
\text { "visitor" and "tourist" (Rome) } \\
\text { Validation of the definition of "international tourist" }\end{array}$ \\
\hline 1968 & $\begin{array}{l}\text { Validation of the definition of "visitor", "tourist" and "excursionist" by the UN Statistical } \\
\text { Commission }\end{array}$ \\
\hline 1975 & $\begin{array}{l}\text { Extraordinary General Assembly of the IUOTO: adoption of the statutes of the World } \\
\text { Tourism Organisation (WTO) and 1st General Assembly in Madrid (current } \\
\text { headquarters) }\end{array}$ \\
\hline 1991 & $\begin{array}{l}\text { Adoption of the resolution on the statistical needs of the tourism sector (International } \\
\text { Conference on Travel and Tourism Statistics in Ottawa) } \\
\text { Choice to rely on the experience of certain states (including France and Canada) for } \\
\text { the establishment of "National Tourism Satellite Accounts" (NTS) }\end{array}$ \\
\hline 1993 & $\begin{array}{l}\text { UN Statistical Commission approval of Ottawa recommendations } \\
\text { Proposal of the foundations of the tourism statistics system: concepts, definitions, } \\
\text { indicators and classifications, including SICTAT or CITAT for "International } \\
\text { Standard Classification of Tourism Activities" (Bali) } \\
\text { Integration of these recommendations by the EEC Council in } 1995\end{array}$ \\
\hline 1999 & $\begin{array}{l}\text { Approval of the "Tourism Satellite Account" (TSA) at the World Tourism Conference } \\
\text { (Nice), approved in } 1997 \text { for OECD countries }\end{array}$ \\
\hline 2001 & $\begin{array}{l}\text { TSA 2001: Approval by the United Nations Statistical Commission of the } \\
\text { international standards for the "Tourism Satellite Account" (CST) }\end{array}$ \\
\hline $\begin{array}{l}2005- \\
2007\end{array}$ & $\begin{array}{l}\text { Work on the preparation of a consensual framework for the evaluation and analysis of the } \\
\text { tourism economy by the international community under the aegis of UNWTO. }\end{array}$ \\
\hline 2008 & $\begin{array}{l}\text { IRST 2008: International Recommendations for Tourism Statistics (Glossary of harmonised } \\
\text { and usable definitions and classifications for all national and international tourism statistics } \\
\text { systems) } \\
\text { Published by the UN Economic and Social Affairs Commission in } 2016\end{array}$ \\
\hline
\end{tabular}


The four statistical reference units: traveller, visitor, tourist and excursionist

On the basis of the conclusions that UNTWO has sought to collect in the IRTS 2008, the definitions distinguish four statistical units: the traveller, the visitor, the tourist, and the excursionist. Extracted and translated from Annex 1 of the version published by the United Nations, in the four definitions we are now quoting, the words in italics correspond to the key ideas and terms underlying these conceptualizations.

(i) The traveller ("traveller"):

A traveller is a person who travels between different geographical locations for any reason and for any duration (IRTS 2008, para.2.4).

This definition includes, in travellers, people in migration, which required, since 1993, to distinguish tourist flows within other flows related to international migration. To identify the tourist among other travellers, it is therefore necessary to go further and make more precise categorizations (those below).

(ii) The visitor ("visitor"):

According to IRTS 2008 (para. 2.9), a visitor is a traveller who travels to a main destination, different from his or her usual environment, for less than one year, for http://ojs.unud.ac.id/index.php/eot any reason whatsoever (business, leisure or other personal purposes) as long as it is not to be employed by an entity resident in the country or place concerned. Visitor trips are tourist trips (IRTS 2008, para.2.29).

\footnotetext{
- The tourist ("tourist" or "overnight visitor"):
}

According to the IRTS 2008 (para. 2.13), a tourist is a visitor (domestic, entering or leaving the country or region in question) whose trip includes at least one overnight stay at destination. But his stay in the destination must not exceed one year.

(iii) The excursionist or same-day visitor

An excursionist is a visitor (domestic, entering or leaving the country or region in question) whose journey takes place during the day. This round trip on the same day means that there is no overnight stay in the main destination. This is the main distinction made with tourists (IRTS 2008, para.2.13).

While this distinction makes sense for the estimation of paid nights and the full calculation of the economic benefits for the host destination, it does not necessarily imply major differences in the visitor's activities. Indeed, whether with or without overnight stay, the excursionist and the e-ISSN: 2407-392X. p-ISSN: 2541-0857 
tourist are two visitors who can present extremely similar profiles in terms of motivations to come and activities (discovery of high places, participation in fairs and events) and types of consumption (purchases of tourist guidance services, purchases of private transport services, food purchases in CHR, coffee hotels and restaurants, or VAE, takeaway sales, souvenir purchases).

\section{The perimeters of the tourist's characterization}

The key elements to be taken into account to distinguish the tourist from other travellers are therefore the trip that refers to the spatial perimeter, the duration of the trip that refers to the temporal perimeter, and the function of the trip that refers to the activities and motivations of the visitor. After placing these three criteria in the process of distinguishing the tourist from other travellers, the implications of these three perimeters are detailed.

\section{Three criteria to distinguish the tourist from other travellers}

The French version of the glossary of statistical measurement elements for tourism is entitled "comprendre le tourisme" (OMT, 2008). In his http://ojs.unud.ac.id/index.php/eot introduction, he recalled that "tourism is a social, cultural and economic phenomenon that involves the movement of people to countries or places outside their usual environment for personal, professional or business purposes. These people are called visitors (and can be tourists or excursionists, residents and non- residents) and tourism refers to their activities, some of which involve tourism spending.

We are talking about tourists and excursionists, but also residents and nonresidents. To capture what distinguishes them from each other, and taking into account the four fundamental statistical units of the traveller, visitor, tourist, and excursionist, Figure 1 shows the importance of the following elements: 1) the movement of the place where one usually lives (i.e. where we are considered inhabitants), 2) the reason for this trip and, in particular, the fact of not being forced or wishing to leave this place permanently, and 3 ) the duration of this trip, in terms of maximum duration (3a) to differentiate between the tourist and the resident, and minimum duration (3b) to identify excursionists among tourists. 


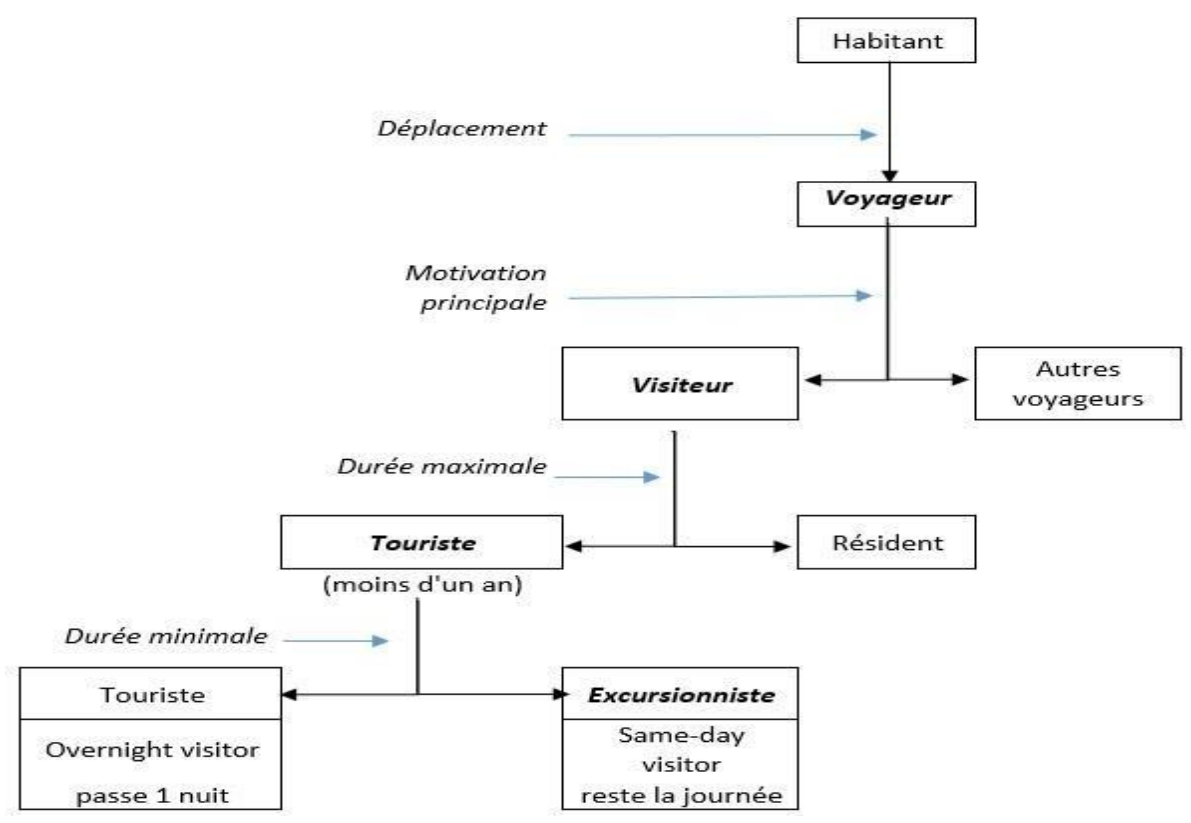

Figure 1. How to move from being a resident to being a tourist?

\section{From concepts and classifications to fluctuating indicators}

As already noted, the UNTWO definitions are based on concepts and classifications aimed at differentiating tourism flows and activities from other migratory flows and at assessing the importance of the tourism-related labour market. Thus, taking into account the classifications and indicators used for other economic activities, it is necessary to be able to incorporate the measurement of tourism into all countries' national accounts and to promote the comparability of results between nations.
However, these international harmonization efforts are hampered by the reality of local diversity. Indeed, there are sometimes major disparities between countries, in population density, accessibility to transport modes, cultural behaviour, and distances between administrative and national borders. For example, the distances to be covered when travelling in Cyprus, the United States or Finland are not easily comparable, neither in terms of distance per kilometre, nor even in terms of travel time (especially if the weather of the season has an impact on travel times and modes). Therefore, the criterion of distance in kilometres may not be of any use in characterizing the usual environment, one of the concepts essential to the definition of a tourist. 
As an illustration, Table 2 presents the variations identified by the Ministry of Tourism of Egypt on the criteria that are used to define what this concept of "the usual environment" means. It shows that each country defines this concept in a specific way. Sometimes, the specification is a single criterion. Sometimes it is multicriteria. Although using a unifying concept, the criteria used to operationalize this same concept are different from one country to another.

\section{The necessary variability of indicators to adapt to each country}

As already noted, the proposed and internationally appropriate definitions recommend that the same concepts be used. Thus, let us recall here the definition (IRTS 2008, para. 2.9 and para. 2.13) which stipulates that one is a tourist if one is "a visitor who spends less than one year and more than one night at destination, i.e. that one is a traveller who moves to a

Table 2. Different choices in the criteria used to define the same concept from the definition of tourist

The criteria used to define the concept of the usual environment

\begin{tabular}{|c|c|c|c|c|c|}
\hline Country & $\begin{array}{c}\text { Distance } \\
\text { (in } \mathrm{km})\end{array}$ & $\begin{array}{c}\text { Administrative } \\
\text { borders }\end{array}$ & $\begin{array}{c}\text { Respondents' }^{\prime} \\
\text { self-assessment }\end{array}$ & $\begin{array}{r}\text { Frequenc } \\
\text { y of visit }\end{array}$ & $\begin{array}{l}\text { Duration } \\
\text { (in hours) }\end{array}$ \\
\hline $\begin{array}{l}\text { South } \\
\text { Africa }\end{array}$ & 50 & & & & \\
\hline Germany & & $\sqrt{ }$ & $\sqrt{ }$ & & \\
\hline $\begin{array}{l}\text { Saudi } \\
\text { Arabia }\end{array}$ & 80 & & & Once a month & \\
\hline Austria & & $\sqrt{ }$ & $\sqrt{ }$ & twice a month & \\
\hline Chile & & & & once a week & \\
\hline Cyprus & 50 & & & Daily & \\
\hline Spain & & & $\sqrt{ }$ & & \\
\hline $\begin{array}{l}\text { United } \\
\text { States }\end{array}$ & $\begin{array}{l}80- \\
120\end{array}$ & & & & \\
\hline Finland & & & & once a week & \\
\hline France & 100 & & $\sqrt{ }$ & & \\
\hline Indonesia & 100 & $\sqrt{ }$ & $\sqrt{ }$ & & \\
\hline Ireland & & & $\sqrt{ }$ & once a week & \\
\hline Israel & & & $\sqrt{ }$ & & 5 \\
\hline Latvia & & $\sqrt{ }$ & $\sqrt{ }$ & Daily & \\
\hline Netherlands & & & & & 2 \\
\hline Portugal & & & $\sqrt{ }$ & & \\
\hline $\begin{array}{l}\text { Czech } \\
\text { Republic }\end{array}$ & & $\sqrt{ }$ & $\sqrt{ }$ & once a week & 3 \\
\hline $\begin{array}{l}\text { United } \\
\text { Kingdom }\end{array}$ & & & & & 3 \\
\hline Slovenia & 50 & & & \multicolumn{2}{|c|}{10 times for 3 months } \\
\hline Sweden & 50 & & & & \\
\hline Switzerland & & & $\sqrt{ }$ & & 4 \\
\hline
\end{tabular}


main place which is different from one's usual environment". However, the establishment and operational specification of these different concepts are not always identical from one country to another. On the contrary, they can fluctuate, which necessarily has an impact on the final qualification of who is a tourist.

But then, if the operationalization of the concepts of the tourist definition varies from one country to another, how can we be sure that the tourist is defined in a harmonized way at the international level? Can we really compare the statistical results of different countries? More generally, can we rely on these definitions?

The answer to this essential question of the reliability of international definitions of tourist is fortunately positive. Indeed, although worrying at first sight, the national variability of the indicators for the technical implementation of the characterization of the mobilized concepts is in fact a guarantee of finesse in the local granularity of the international definition of the tourist.

If we take again the example of the comparison between Cyprus, the United States and Finland, the distance per kilometre makes sense in the United States where roads are generally accessible all http://ojs.unud.ac.id/index.php/eot year round and where both motorway and car equipment are important when, on the other hand, the criteria used will add a notion of daily regularity of travel for Cyprus, and prefer the notion of weekly frequency for Finland only.

Thus, each country offers criteria adapted to its geomorphological originality, but also to the cultural habits, residential leisure practices and the usual forms of local mobility of its inhabitants. This is particularly relevant for considering global studies on international tourist activities (i.e. taking into account what is technically possible to do in each destination according to its local characteristics) but also for comparisons of the practices and performances of domestic tourism (i.e. taking into account what is recurrent to find in the holiday and tourist practices of the different countries and geographical areas considered).

In conclusion, behind the variability of the indicators used by each country, there is always the ambition to have locally relevant information to find the meaning associated with the concepts underlying the international definition of tourist. In the case of the usual environment (Table 2), all countries have endeavoured to identify criteria that would enable them not to assimilate the tourist to a resident, and to be assured that the host 
destination is indeed different from that of a place of customary life. Even if it is expressed differently in each country, this idea of the unusual, which is based on the observation that there is always a part of the quest for an alternative place symbolically different from the tourist's daily life (Boyer, 2011), is therefore always well taken into account.

The researcher and the practitioner can therefore rely on the statistical definitions and operationalizations, as designed by UNTWO, for their work and studies since they effectively make it possible to find the important characteristics of the tourist.

The stability of the three perimeters to be considered to characterize the tourist

Qualified here as perimeters since they allow the tourist to be located in relation to other residents and inhabitants and in relation to other travellers, the consideration of three elements allows a tourist to be well characterized. Insofar as these three elements have always been used to describe a tourist (Boyer, 2005), and insofar as these three elements remain stable and valid in all countries of the world, they represent the opportunity to consider ontologically the status of tourist.
These three perimeters are: 1) the spatial perimeter with the notion of displacement; 2) the temporal perimeter with the notion of the duration of the displacement, and 3) the functional perimeter. The latter perimeter refers to the function of travel for the traveller, i.e. the motivations for his or her travel and the activities he or she engages in during the trip.

Their consideration allows for a shortened qualification, or even an ontology of the "tourist being", which could be the following: the tourist is an individual, from elsewhere, who will not settle down, and who acts in a particular way on the spot.

We specify below these three perimeters and what we must try to capture beyond the variations in the indicators for those who want to carry out studies and research on tourism as a social and cultural fact. The goal is thus to ensure that participants are selected who are indeed individuals with the distinctive characteristics of what a tourist is. 
Spatial perimeter: from the country of residence and the usual environment to the measurement of incoming and outgoing flows

The founding concepts used in tourism statistics, which reflect the spatial dimension, are the terms "reference country", "country or place of usual residence", "principal residence" and "nationality".

Be outside the place of residence and the usual environment

These concepts in relation to the residence make it possible to classify visitors according to their place of origin and therefore to specify the different forms of tourism. A clear distinction must be made and the notion of place of residence must be given priority over that of nationality. Nationality refers to the information available on the passport or other administrative document. Conversely, the place of usual residence, or principal residence, is the geographical location where the person resides most regularly. This concept is less definitive and more flexible than that of nationality.

A step further, the notion of the individual's usual environment, a key concept to define the tourist that we have already mentioned, refers to the geographical area, which is not necessarily continuous, within which the individual carries out the routines of a regular life.
It is therefore the fact that the individual is spatially outside the geographical spaces associated with the regularity of a routine rhythm of life that allows him/her to be granted the status of a tourist.

This characterization by the spatial perimeter outside its usual environment aims to exclude from the tourism accounts, individuals who travel in a monotonous and usual way to go from their place of life to their place of employment or study, and, more generally, all those who travel frequently, whatever the spaces considered, according to a routine logic (whether to see their family, go to commercial, medical or religious areas). This applies even if the distance covered is substantial. The usual environment therefore includes the family living space, but also the employment and study areas and all other places visited on a regular basis. One of the purposes of this qualification is to exclude from tourist counts all cross-border workers and all travellers who make round trips for work and study.

\section{Holiday homes and second homes}

Imagine French retirees who spend most of the year in Morocco to enjoy a milder climate. Throughout this winter period, their usual and routine place of residence is Morocco and no longer e-ISSN: 2407-392X. p-ISSN: 2541-0857 
France. Two questions arise here: what is the main place of residence, and how to locate travel to holiday homes?

The issue of principal residence is easy to address since it is sufficient to know where they spend the most time in a year, i.e. at least 6 months and 1 day. Thus, while the concept of the principal residence is primarily spatial, it appears that its practical operationalization requires the introduction of the temporal dimension since the principal residence is where the person spends most of the year.

The issue of holiday homes is more complex since it is a special case of regular travel. Indeed, since these houses and second homes are the object of periodic and recurrent travel, should they be integrated into the usual environment and excluded from tourist trips?

The expenses and activities related to stays in these holiday homes and other second homes appear specific. Therefore, the statistical authorities recommend, to date, to count them as tourist trips but to ensure that they are distinguished within these tourist trips. For example, in France, by convention, travel to a secondary residence is considered to be tourist travel outside the usual environment (Mémento du Tourisme, 2017).
From a practical point of view for the researcher and practitioner, this means that it is important to ask respondents to specify what their accommodation is: Is it a family or secondary residence? Is it a dwelling that he regularly occupies and how many days does he spend there per year?

Finally, in the current context of innovative forms of residential sharing or free accommodation (see couchsurfing), it may be important to cross-reference tourist flow data with data on holiday accommodation at the destination level. Even if this information may seem remote from the initial investigation project, asking about the accommodation chosen is ultimately an important factor to be taken into account in any study aimed at understanding and explaining tourist behaviour.

International inward and outward flow accounting

Among the data related to the spatial perimeter, nationality makes it possible to measure international arrivals. This involves calculating the number of tourists from other countries returning to a given country. On a global scale, this makes it possible, among other things, to identify the most important receiving areas and their evolution in terms of attractiveness (see Figure 2). 
It should be noted that these assessments made at the entrance to a national territory do not represent the number of international visitors but the number of national borders crossed by all visitors. Thus, a German citizen who crosses France by car for a holiday in Spain will be counted twice as an international arrival for France. And this, even if he only transits without staying in France. He will be counted once when he travels from Germany to Spain, and a second time at the end of his holidays when he returns from Spain to Germany.

International tourist arrivals are therefore somewhat biased data that should be considered with caution. What about the real economic benefits of some international arrivals? What relevance would it have to consider development strategies for tourist reception if we were to rely solely on these data?
Tourism typologies resulting from the spatial perimeter

More generally, concepts related to the spatial perimeter make it possible to distinguish the three forms of reference tourism which are:

a. Inbound tourism (inbound tourism). It includes activities related to travel within the site, travel made by nonresident visitors to that reference site.

b. Outbound tourism (outbound tourism). It includes the activities of visitors residing in the reference place when they travel outside that reference place.

c. Domestic tourism (or domestic tourism). It includes the activities of a visitor who is a resident of the reference place when travelling within that reference place.

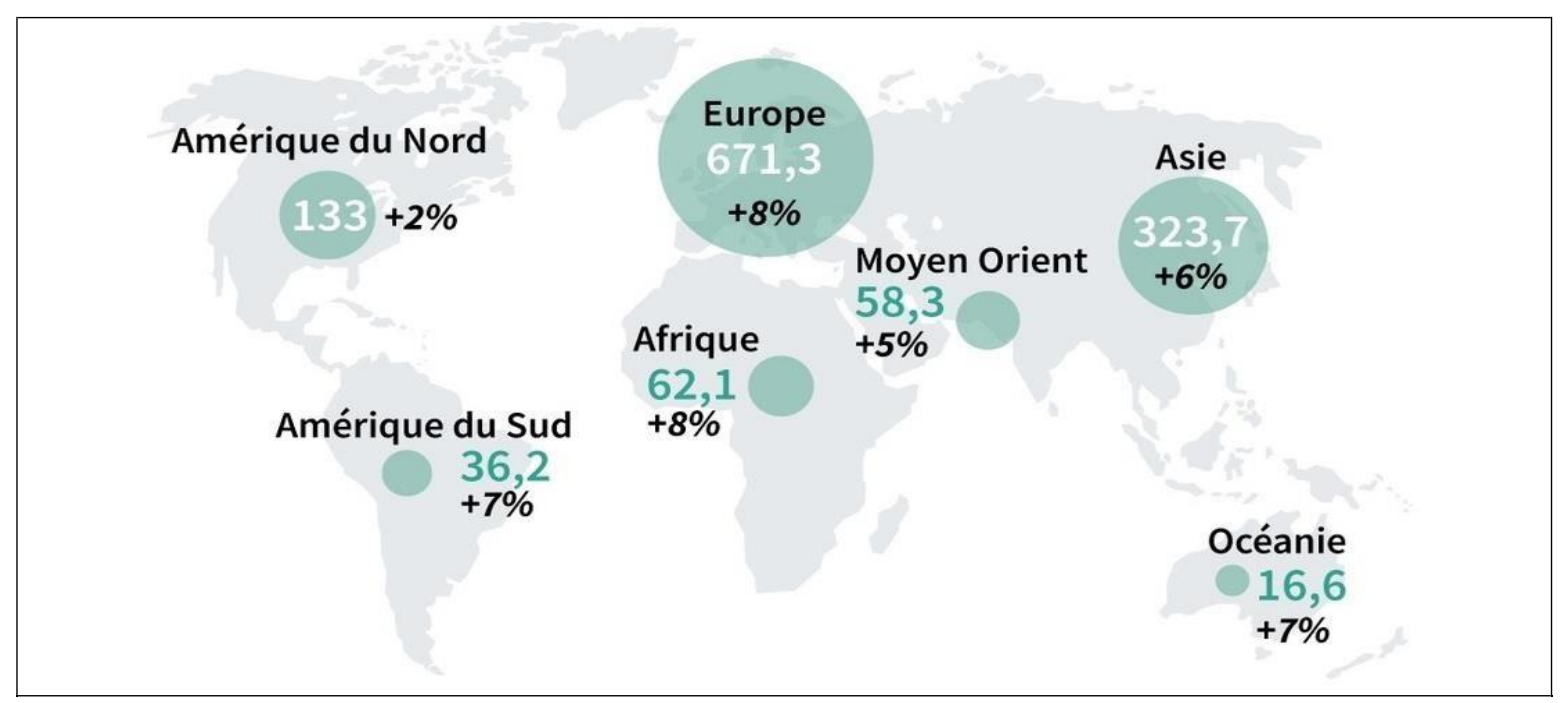

Figure 2. International tourist arrivals in 2017 (in millions) and change from 2016 (in \%) (AFP UNTWO) 
By extension, international tourism includes incoming and outgoing tourism. Domestic tourism includes domestic (resident) and incoming (non-resident) tourism. Finally, national tourism includes domestic and outgoing tourism: the activities of resident visitors during their tourist trips in their reference country and activities related to their tourist trips outside their reference country.

The temporal perimeter: Temporary residence (more than one night and less than one year)

As shown in Figure 1, the temporary nature of the trip is an essential factor in characterizing the tourist. More than one night and less than one year are the consensus rules now systematically applied. These temporal boundaries make it possible to separate tourist visitors from migrants who do not plan to return to their initial place of main residence.

However, a finer temporal granularity than this broad boundary, which ranges from one day to one year, is often useful in order to be able to categorize tourist visitors in order to consider truly adapted reception and development strategies.

Indeed, depending on the duration of travel and stay, visitors' behaviour changes. During the first few days, foreign to the area and unaware of local customs and habits, visitors have needs for assistance and expectations that will evolve as they become accustomed to and immersed in the visiting environment. What is of the order of the unusual will gradually transform into a form of second habitual environment. From then on, their behaviour will change and no longer be that of a first-time visitor.

Therefore, even for visitors who no longer have a principal residence in the administrative sense, the concept of principal residence makes it possible to define what their reference location is. And even for digital nomads, who could be classified as professional holidaymakers (or professionals still on holiday...) since they move from coworkation to coworking areas all over the world all year round (Marinos et al., 2019), it is possible to identify their main place of residence from the area and country in which they have stayed the longest over the past 12 months. It is true, however, that these new professional practices and employment relations question international classifications on tourist travel. 
The functional perimeter: The activities and motivations of the tourist

Faced with the complexity of the tourism object, Georges Cazes (1992) stresses the importance of taking into account the functions of tourism for the traveller. The last of the three principles that distinguish tourists from other travellers and visitors is therefore that of motivations and activities (i.e. the functional perimeter).

Indeed, in relation to the expectations he places in his trip and taking into account the reality of his practices during the trip and stay, the tourist adopts a different behaviour from other travellers. Its buyer profile and consumption are specific. And behavioural differences are expressed in the choice of activities. Among these, among others, there is a part, sometimes minimal but almost always present, of research to discover local culture.

It is in this logic of qualifying the tourist by his practices during the trip that the concept of "main reason for the tourist trip" has been proposed. It should be considered that, without this main reason, there would not have been any travel (IRTS 2008, para. 3.10.).
Beyond the positive list of personal reasons and goals that may govern the intention to travel (see Box 1), it is also necessary to highlight the criterion that excludes from tourist status. This excluding criterion is that of having an employer-employee relationship with an entity resident in the destination visited. A seasonal employee may behave in a similar way to a tourist since, during these holidays, he or she may seek to discover the local culture and visit the tourist highlights of the place of employment. While, in this respect, it seems appropriate to associate it with tourists to study their common expectations of discovering local heritage and culture, by convention, it is now considered that a seasonal employee should never be considered and measured as a tourist.

As already mentioned above, this criterion of the relationship to employment is undoubtedly the one that could in the future be called into question or, at least, re-defined and adapted to match current and future developments in forms of work. Finally, in order to consider strategies to enhance the attractiveness of destinations that are perfectly adapted to the specificities and expectations of the targeted visitors, according to a segmented marketing approach (Petr, 2015), in addition to the main reason for travel, it is 
necessary to identify and also consider the secondary activities carried out by tourists. This is particularly relevant for studies aimed at managing the attractiveness of the destination.

\section{Box 1 -The main reason for a tourist trip}

The main reason for a tourist trip is defined as the main reason why the trip would not have taken place without it.

A tourist is a visitor (domestic, entering or leaving the country or place in question) who comes for any reason whatsoever: business, leisure or other personal purposes.

\section{The 9 categories of the tourist travel classification:}

1. Business and professional reasons (meetings, conferences or congresses, trade fairs and exhibitions, and other business and professional reasons)

2. holidays, relaxation and leisure (in English, the notion of "recreation" is added, which suggests a practice in natural spaces)

3. visit friends and relatives

4. education and training

5. health (thermalism, thalassotherapy,etc)

6. religion and pilgrimages

7. shopping

8. transit

9. other reasons

\section{CONCLUSION}

It can be conclude that contextualized and recalled the definitions of tourists based on the recommendations made since IRTS 2008 by the supranational organization for the promotion of tourism on a global scale (UNTWO).

These reminders were an opportunity to highlight the importance of allowing nations flexibility in the operationalization of the criteria to be mobilized for the founding concepts used to define tourists. It is important that each country be able to adapt, to its regional and national originality, the technical implementation of the concepts underlying the statistical measures of tourism. The prerequisite for this local flexibility is that the principles and meaning of these internationally defined concepts are well understood and uniformly shared.

In addition, the mention of the different perimeters to be considered highlighted some traveller configurations that need to be carefully examined during studies and research, such as retirees, cross-border workers or seasonal employees. This vigilance ensures that volume and flow measurements are accurate, and that subsequent assessments of the significance of the economic, social 
and cultural impact potentially induced by tourism activity are not underestimated or, on the contrary, overestimated. Beyond these guarantees of good estimates, taking into account the ideas underlying these perimeters also provides the certainty of carrying out valid sampling for research work on tourist populations.

In perspective, we suggest that readers, researchers and practitioners consider and mobilize more subjective dimensions to assign an individual the status of tourist, in addition to the objective categories already used, spatial, temporal and by activities. These subjective complementary measures include, on the one hand, mental representations relating to the imaginary of the tourist character (i.e. the figure of the tourist), and on the other hand, those dealing with the "feeling of being (or not) a tourist" and individual acceptance or denial of being a tourist. Thus, among those who can, objectively and statistically, be classified in the "tourist" box, who really perceives themselves as tourists? What does this mean for him?

Considering this theme of representations of the tourist and being a tourist, it is a question of studying the tourist phenomenon from the point of view of the person who lives this travel experience, i.e. the tourist, but also from the point of view of the person who receives this visitor, i.e. the habitant. The study of dyadic relations between tourists and inhabitants seemed to be reserved for executives from distant and developing countries, subject to the pressure of tourist arrivals sometimes perceived as intrusive or colonialist. This problem seems to be spreading today to the Western world, which is nevertheless used to tourism (Martinez-Garcia, Raya, Majó, 2016; Petr, 2018).

In view of the continuous growth and unfailing resilience of tourism (Babu and Callot, 2019), and in view of the various anti-tourism measures or reactions recently expressed by inhabitants of various key destinations in Europe such as Barcelona, Dubrovnik, Venice, or even Bordeaux, etc., could the issue of tolerance and the feeling of tourist invasion by the inhabitants of old Europe become an investigation subject that will soon become impossible to ignore?

\section{REFERENCES}

Boyer M. (1972), Le tourisme, Le seuil, Paris.

Boyer M. (2005), General History of Tourism from the 16th to the 21st Century, L'Harmattan. 
Boyer M. (2011), Ailleurs : Histoire et sociologie du tourisme, L'Harmattan. Babou I. and Callot P. (2019), Tourism: Stop or even? Les Editions Baudelaire, Lyon.

Cazes G. (1992), Fondements pour une géographie $d u$ tourisme et des loisirs, Edition Bréal, Paris.

Demen-Meyer C. (2005), Tourism: Essay on definition, Management \& Future, 1(3), 7-25.

Marinos C., Mahéo C., Gourlay F. Petr C. (2019), When co-working is no longer enough, we go further! Exploratory study of the quarters, 17th Seminar of Marsouin, Usages \& NTIC, Rennes (35), 23-24 May.

IRTS 2008 Compilation Guide (2016), International Recommendations for Tourism Statistics 2008 Compilation Guide, Department of Economic and Social Affairs, Statistics Division, Studies in Methods, United Nations Publication, ST/ESA /STAT/SER .M/94, New York.

Leiper N. (1993), The framework of tourism: towards a definition of tourism, tourist, and the tourist industry, Annals of Tourism Research, 4(6), 390-407.

Liburd J.J (2002), Tourism in a global society, Annals of Tourism Research, 23(5), 882-884.

Martinez-Garcia E., Raya J.M. et Majó J. (2016), Differences in residents' attitudes towards tourism among mass tourism destinations, International Journal of Tourism Research, 19, 535-545.
UNWTO (2008), Understanding Tourism: Basic Glossary, Accessed online June 21, 2019: http://cf.cdn.unwto.org/sites/all/files/ docpdf/glossaryfrrev.pdf.

Petr C. (2018), Why is tourism unloved? Why do we have to justify tourism? Discussion on the disenchantment of the journey of the Other, Les Hippocampes $d u$ Golfe $d u$ Morbihan, Vannes, University of South Brittany, 8 November 2018. Petr (2015), Le marketing $d u$ tourisme, Dunod, Paris.

PY P. (2007), Le tourisme : un phénomène économique, La Documentation Française, Paris.

Williams S. (2004), Critical concepts in the social Sciences: Tourism, Routledge, London. 